\title{
Laypersons can successfully place supraglottic airways with 3 minutes of training. A comparison of four different devices in the manikin
}

\author{
Gereon Schälte ${ }^{1 *}$, Christian Stoppe ${ }^{1}$, Meral Aktas ${ }^{2}$, Mark Coburn ${ }^{1}$, Steffen Rex ${ }^{1}$, Marlon Schwarz ${ }^{1}$, Rolf Rossaint ${ }^{1}$ and \\ Norbert Zoremba'
}

\begin{abstract}
Introduction: Supraglottic airway devices have frequently been shown to facilitate airway management and are implemented in the ILCOR resuscitation algorithm. Limited data exists concerning laypersons without any medical or paramedical background. We hypothesized that even laymen would be able to operate supraglottic airway devices after a brief training session.
\end{abstract}

Methods: Four different supraglottic airway devices: Laryngeal Mask Classic (LMA), Laryngeal Tube (LT), Intubating Laryngeal Mask (FT) and CobraPLA (Cobra) were tested in 141 volunteers recruited in a technical university cafeteria and in a shopping mall. All volunteers received a brief standardized training session. Primary endpoint was the time required to definitive insertion. In a short questionnaire applicants were asked to assess the devices and to answer some general questions about BLS.

Results: The longest time to insertion was observed for Cobra (31.9 \pm 27.9 s, range: 9-120, $p<0.0001$; all means \pm standard deviation). There was no significant difference between the insertion times of the other three devices. Fewest insertion attempts were needed for the FT $(1.07 \pm 0.26)$, followed by the LMA $(1.23 \pm 0.52, p>0.05)$, the LT $(1.36 \pm 0.61, p<0.05)$ and the Cobra $(1.45 \pm 0.7, p<0.0001)$. Ventilation was achieved on the first attempt significantly more often with the FT $(p<0.001)$ compared to the other devices. Nearly $90 \%$ of the participants were in favor of implementing supraglottic airway devices in first aid algorithms and classes.

Conclusion: Laypersons are able to operate supraglottic airway devices in manikin with minimal instruction. Ventilation was achieved with all devices tested after a reasonable time and with a high success rate of $>95 \%$. The use of supraglottic airway devices in first aid and BLS algorithms should be considered.

\section{Introduction}

The securing of the airway and ventilation of the lungs is of paramount importance following initial chest compressions during cardiopulmonary resuscitation (CPR). In the preclinical setting, physical contact with the patient (in particular their mouth) presents a strong deterrent to many lay responders. Disgust and fear of infection, associated with contact with bodily fluids are frequently cited as preventing immediate care [1-3]. This may coincide with a fear of incorrect mouth-to-

\footnotetext{
* Correspondence: gschaelte@ukaachen.de

'Department of Anesthesiology, University Hospital Aachen, Aachen, Germany

Full list of author information is available at the end of the article
}

mouth ventilation and potential malpractice consequences.

To facilitate mouth-to-mouth ventilation in case of out-of-hospital CPR several products are available. These products are based on the principle of either covering the mouth and/or face with a drape, or covering the nose and mouth via facemask with a mouth adapter. All devices are equipped with a protective filter system. Achieving adequate ventilation (without gastric inflation) is dependent on the seal of either face mask or drape, manual skills, and the acceptance of close physical contact with a stranger and the associated risks [3]. Independent of the type of device, it must be readily available, e.g. close to automatic external defibrillators 
(AEDs), or carried in the pocket in readiness for emergencies.

For both junior and experienced medical personnel, supraglottic airway devices have frequently been shown to facilitate airway management. Therefore, the laryngeal mask and laryngeal tube are implemented in the American Society of Anesthesiologists (ASA) algorithm for the management of the difficult airway and the International Liaison Committee on Resuscitation (ILCOR) algorithm for cardiopulmonary resuscitation [4]. In both, manikin and clinical studies, Paramedics, nurse and (para-) medical students have been shown to secure the airway and ventilate the lungs faster and more effectively when using a supraglottic airway device compared to mouthto-mouth ventilation [5-8]. In a recently published study we demonstrated that even without any instruction, first year medical students were able to insert a supraglottic airway device intuitively with a reasonable speed and success rate. After a minimal well directed training, insertion times and success rates can be markedly improved [9].

We therefore hypothesized that even laypersons without any medical background would be able to operate supraglottic airway devices following brief instruction.

The aims of this study were: 1 ) to test whether lay persons are able to secure the airway and ventilate the lungs adequately using a supraglottic device following a brief training session of 3 minutes; and 2) to compare four supraglottic devices with regard to practicability: Laryngeal Mask Classic ${ }^{\circledR}$ (LMA) and Laryngeal Mask Fastrach $^{\circledR}$ (FT) (both: LMA Deutschland GmbH, Bonn, Germany), Laryngeal Tube ${ }^{\circledR}$ (LT) (VBM Medizintechnik GmbH, Sulz, Germany), CobraPLA ${ }^{\circledR}$ (Cobra) (Engineered Medical Systems, Indianapolis, IL, USA).

\section{Methods}

The institutional review board waived the requirement to obtain written informed consent from the participants as no personal data except age and first aid knowledge were collected, and no influence on the participants' health was expected. All subjects agreed for their performance to be evaluated and anonymously used for scientific and educational purposes. Prerequisites for inclusion were the lack of any previous medical education (i.e. physician, nurse, EMT, paramedic) other than a "first-aid" course, and an age of 16 or older.

Applicants were recruited in a public shopping mall and in the central cafeteria of the RWTH Aachen University campus. Experimental data were recorded "on-site".

Four different supraglottic airway devices (LMA, LT, FT and Cobra) were investigated. The order in which devices were presented was rotated after every 35 participants to eliminate any bias. A resuscitation scenario with a manikin (Ambu Airway Man ${ }^{\circledR}, \mathrm{Ambu} \mathrm{GmbH}$,
Bad Nauheim, Germany) laying on the floor was prepared. All participants received a single minimal standardized training session "hands off" before their individual trial. The instructions comprised the following sentences: "This patient is in respiratory arrest. He has stopped breathing and you must begin ventilation immediately. Much better and more efficient than mouth-to-mouth ventilation is the use of one of these 4 devices (demonstrated). Simply take one of them, insert it into the mouth of the patient, with the opening facing in the same direction as the "belly button" until you feel resistance, connect the syringe, inflate the balloon to form a seal (demonstrated with the LMA), connect the bag-valve and start to ventilate the manikins lungs by compressing the bag gentle but full squeeze (two hands, demonstrated). If the thorax does not expand and this indicator (shown) does not show green or yellow, immediately take the device out, deflate the balloon, and start again (demonstrated)". The procedure was thus demonstrated step by step during the verbal instructions. We chose the LMA for demonstration representing the eldest and most reviewed modern supraglottic airway device. At the end the procedure was demonstrated again from start to finish. Thereafter, no further questions were answered, nor was the demonstration repeated on request. Immediately following insertion of the device a prepared syringe with the designated correct air volume was connected, the cuff was inflated, and the time to first manual ventilation was recorded. The volume of air inflated (Ambu Airway Man ${ }^{\circledR}$ scale) was measured and any eventual leak estimated. The cuffs of all supraglottic devices were inflated with the maximum volumes of air recommended by the manufacturer (LMA size 4 and FT size 4 with $30 \mathrm{ml}$ each, Cobra size 4 with $70 \mathrm{ml}$, and LT size 4 with $80 \mathrm{ml}$ ). A single trial was aborted after 2 minutes or more than 3 failed attempts.

A tidal volume of $>500 \mathrm{ml}$ was considered as sufficient according to the ERC resuscitation guidelines. A tidal volume of less than $<500 \mathrm{ml}$ was deemed insufficient. An expiratory tidal volume $>800 \mathrm{ml}$ was classed as no leakage, $500-799 \mathrm{ml}$ as minor leakage and $<500$ $\mathrm{ml}$ as major leakage.

To eliminate the bias of a potential learning curve by the sequence supraglottic devices were changed in random-order. None of the participants could watch the trial of any other participator. Partition panels were used to separate and hide the resuscitation scenario.

At the end, individuals were asked which of the 4 devices they preferred. Finally 5 questions concerning resuscitation had to be answered yes or no.

1. If emergency resuscitation kits including a bagvalve and a supraglottic airway device were available 
in public places, e.g. sports facilities or at your workplace, do you believe you would be able to use them to deliver adequate lung ventilation?

2. Do you believe that the combination of a supraglottic airway device and a bag-valve can be used by lay responders during resuscitation reasonably?

3. Should this kind of lung ventilation be taught in first aid classes?

4. Do you think that this type of lung ventilation would make you more willing to deliver lung ventilation during cardiopulmonary resuscitation?

\section{Statistics}

A success rate of $95 \%$ was expected $[10,11]$. The power of the study was calculated with a significance level, $\alpha=$ 0.05 . The equivalence limit difference, $\mathrm{d} 0$ was assumed to be 7 and the expected difference, $\mathrm{d} 1$ was set to be 0 . A power of $80 \%$ results in a sample size of 120 . In total 141 study subjects were included to compensate for possible dropouts. The power calculation was performed using nQuery Advisor ${ }^{\mathbb{B}}$ Version 7.0 (Statistical Solutions, Saugus, MA, USA).

Statistical analysis was performed using GraphPad Prism 5.0 for Mac (GraphPad Software, San Diego, CA, USA). Metric scaled data were analyzed calculating mean and standard deviation. Analysis of variance (ANOVA) with Bonferoni correction for multiple comparisons was used to detect statistical differences between the groups. To analyze the variation in repeated measures of tidal volume, number of attempts, and time to insertion, Friedmann's test with Dunn's correction was used. The level of significance was set at $5 \%$ for these four variables. A P of $1 / 4 * 5 \%=0.0125$ indicated statistical significance. A chi-square test was used to detect statistical differences in contingent data.

\section{Results}

Data from 141 subjects (65 women, 76 men) were analyzed. None of these had any previous medical or paramedical education. In addition $19.1 \%(n=27)$ of these individuals had never participated in a first-aid course, whereas a first aid course had been taken more than 10 years ago in $13.5 \%(\mathrm{n}=19), 2-10$ years ago in $43.3 \%(\mathrm{n}$ $=61)$ and less than 2 years ago in $24.1 \%(\mathrm{n}=34)$ of the participants (Table 1).

Neither first-aid training itself nor how current this was correlated either with the time to insertion ( $\mathrm{p}=$ 0.29 ) (Figure 1) or the number of attempts required ( $\mathrm{p}$ $=0.25$ ) (Figure 2).

A comparison of the insertion times between the LMA, the LT, the FT and the Cobra devices showed the Cobra to need the longest time for insertion ( $\mathrm{p}<$ 0.0001). No statistically significant differences between
Table 1 Demographical data and previous first aid knowledge

\begin{tabular}{lc}
\hline Characteristics & \\
\hline Age, $y$ & $24.96 \pm 8[16-73]$ \\
Sex & 65 \\
female, $n$ & 76 \\
male, $n$ & \\
First aid education, $n$ & $27(19.1 \%)$ \\
no & $34(13.5 \%)$ \\
$<2$ years & $61(43.3)$ \\
$2-10$ years & $19(13.5 \%)$ \\
$>10$ years &
\end{tabular}

Data are presented as mean $+/$ - standard deviation, [range], numbers and (percentage)

the insertion times of the other three devices were found Figure 3).

Regarding ease of insertion, the FT $(1.07 \pm 0.26)$ required fewest attempts, followed by the LMA (1.23 \pm $0.52)$, the LT $(1.36 \pm 0.61)$ and the Cobra $(1.45 \pm 0.7)$. No statistically significant differences could be shown between the FT and the LMA ( $\mathrm{p}>0.05$ ). Compared to the FT the Cobra $(\mathrm{p}<0.0001)$ and LT $(\mathrm{p}<0.05)$ required significantly more attempts for correct placement, but no significant differences between the Cobra, LMA, and LT were found. Significantly more patients were ventilated on the first attempt with the FT ( $\mathrm{p}<$ 0.001) (Table 2). No significant differences in the application of "sufficient" tidal volumes $(>500 \mathrm{ml})$ were found among the 4 devices $(\mathrm{p}=0.08)$. Analysis of subgroups with tidal volumes of $500-800 \mathrm{ml}$ and $>800 \mathrm{ml}$ found significantly smaller (but sufficient) tidal volumes $(500-800 \mathrm{ml})$ in LMA ventilated patients $(\mathrm{p}<0.0001)$

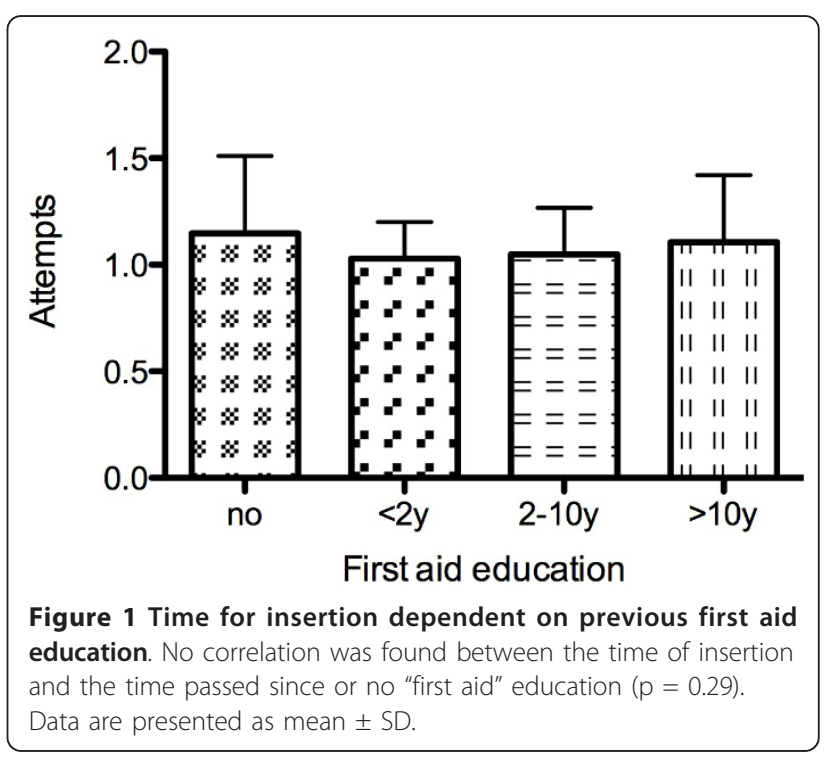




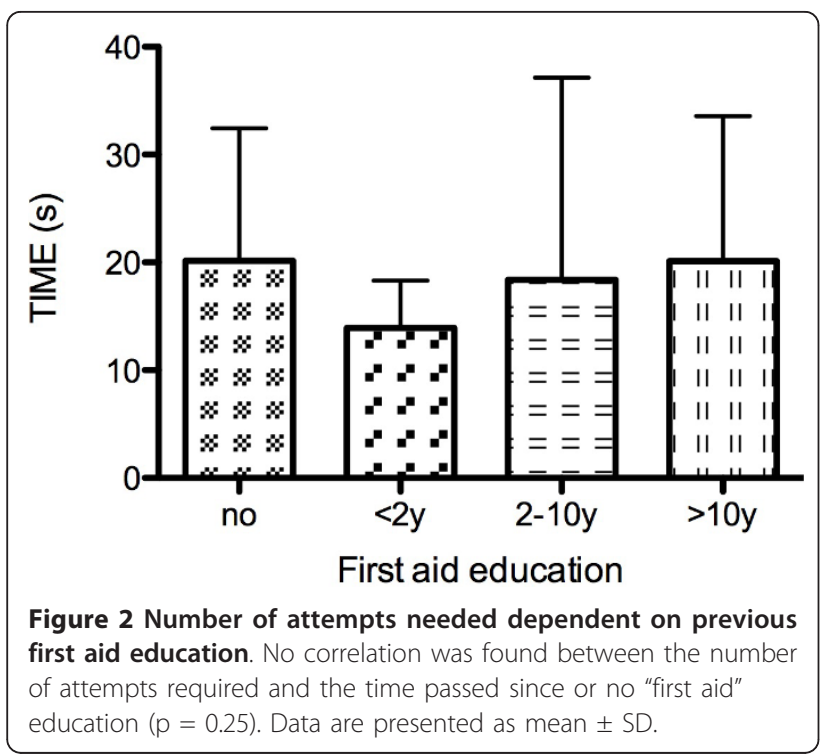

(Figure 4). With all tested supraglottic devices a tidal volume of more than $150 \mathrm{ml}$-the estimated dead spacecould be generated (Figure 5).

In their statements evaluating the 4 devices subjects expressed a preference for the FT $(41.8 \%, \mathrm{n}=59)$, followed by the LMA $(34 \%, \mathrm{n}=48)$, the LT $(20.6 \%, \mathrm{n}=$ $29)$ and the Cobra $(3.5 \%, n=5)$. Commonly cited as supporting their classification were the ease of handling, how intuitive they were to use, and their "grip".

Failed insertions due to incorrectly rotated devices occurred 15 times. All of these occurred in Cobra and on the $1^{\text {st }}$ attempt $\left(6 \times\right.$ upside-down, $\mathrm{p}=0.67 ; 9 \times 180^{\circ}$ dorso-ventral rotation \& 1 combined upside-down, $\mathrm{p}=$ $0.0024)$.

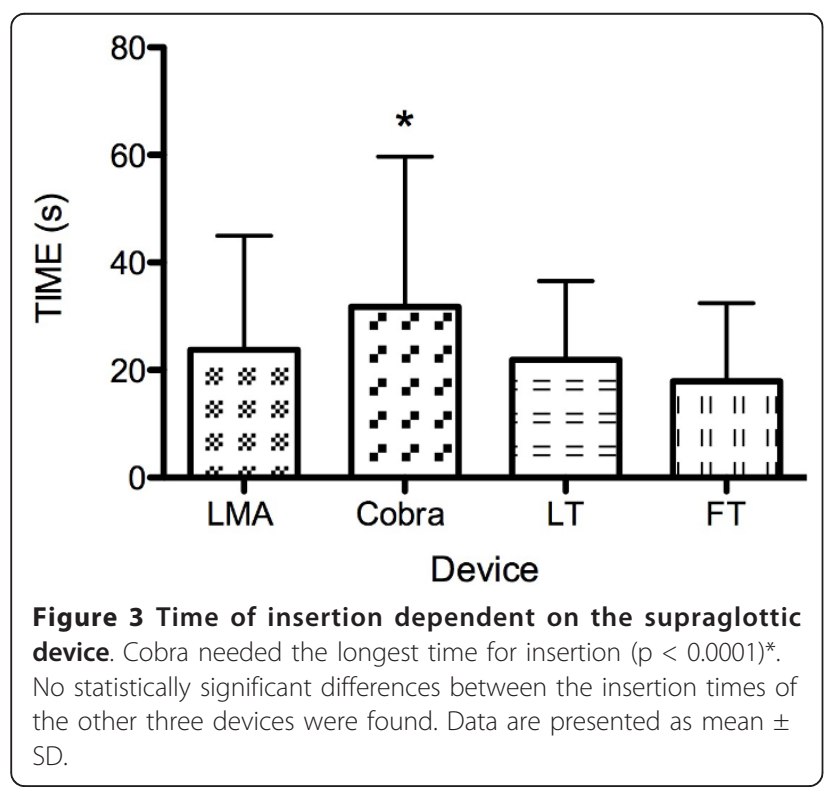

No bias of a potential "learning curve" by sequence of the supraglottic devices could be demonstrated in terms time of insertion and number of attempts (Table 3).

Questionnaire: $67.4 \%$ of the participants felt competent in performing ventilation with a supraglottic airway after this brief training, and $87.9 \%$ judged the combination of a supraglottic airway and a bag-valve to be a useful aid in out-of-hospital resuscitation. Nearly $89.4 \%$ supported the introduction of and briefing with supraglottic airway devices in first-aid courses. Finally, 85.8\% agreed that the availability of these devices would make them more likely to attempt ventilation during cardiopulmonary resuscitation.

\section{Discussion}

In this manikin study, we show that laypersons are able to successfully place a supraglottic airway following minimal training.

This ability was independent of prior first-aid education or its age. Despite the inherent limitations of the scenario (plastic device inserted into plastic mannequin) and the limited malleability of the "oral and supraglottic tissue" of the Ambu Airway Man ${ }^{\circledR}$, we show that all four supraglottic airway devices applied by laymen provided a reasonable airway and allowed for the application of sufficient tidal volumes.

FT performed best with regard to time to insertion, number of attempts required, and in the subjective assessments of the participants. Interestingly, none of the four devices tested actually "failed". A tidal volume of more than the assumed dead space $(<150 \mathrm{ml})$ could always be generated.

In contrast to previous studies, none of our volunteers had any healthcare training other than first aid provider courses. We consider them therefore to act more intuitively and with a lower level of caution than healthcare professionals, who are more familiar with and likely more fearful of potential adverse effects.

Previous studies in patients, cadavers and manikin have all proven LMA, FT, LT and Cobra to be efficient tools for airway management in the hands of naïve "intubators" and inexperienced medical personnel [5,6,12-16]. These studies investigated first year medical, paramedical and nursing students, as well as military personnel in combat paramedical or medical education. In all these subjects we might assume a certain interest in, familiarity with and aptitude for a range of medical procedures and emergencies. In addition, a current certification in first-aid is a prerequisite for all such vocations (whereas it is not required to hold a driving license, for example). Therefore, although not (yet) formally trained in healthcare we might expect such subject populations to perform differently to "true laypersons" as per our definition. 
Table 2 Time of insertion, attemps and ventilation quality (tidal volumes, estimated leakage).

\begin{tabular}{lcccc}
\hline & LMA & Cobra & LT & FT \\
\hline Time to insertion & $23.8 \pm 21.2(17)[9-120]$ & $31.9 \pm 27.9(19)[9-120]$ & $21.9 \pm 14.7(15)[8-75]$ & $17.9 \pm 14.6(15)[8-120]$ \\
Success, $\mathrm{n}$ & $138(97.1 \%)$ & $105(95.8 \%)$ & $139(98.6 \%)$ & $141(100 \%)$ \\
Leakage, tidal volumes & & & & \\
$\quad$ no, $>800 \mathrm{ml}$ & $36(25.5 \%)$ & $96(68.1 \%)$ & $97(68.8 \%)$ & $107(75.9 \%)$ \\
$\quad$ minor, $500-800 \mathrm{ml}$ & $101(71.6 \%)$ & $39(27.7 \%)$ & $42(29.8 \%)$ & $34(24.1 \%)$ \\
$\quad$ major, $<500 \mathrm{ml}$ & $4(2.8 \%)$ & $6(4.3 \%)$ & $2(1.4 \%)$ & 0 \\
Attempts, $\%$ & & & & \\
$\quad 1^{\text {st }} / 2^{\text {nd }} / 3^{\text {rd }}$ & $80.9 / 14.9 / 4.3$ & $66.7 / 22 / 11.3$ & $71.6 / 21.3 / 7.1$ & $92.9 / 7.1 / 0$ \\
\hline
\end{tabular}

Tidal volumes $>500 \mathrm{ml}$ were quoted sufficient according the ILCOR guidelines. With all devices a tidal volume greater than $150 \mathrm{ml}$ (estimated dead space) could be applied. Data are presented as mean +/- standard deviation, (median), [range] and number.

In the present study more than $58 \%$ of the participants had not attended a first aid course in the past 2 years and 19\% had no first aid training at all. (Only $23 \%$ of subjects had attended a first-aid course within the past 2 years). Beauchamp et al. as well found a high success rate independent from previous "first-aid" education [17].

To the best of our knowledge, this is the first study comparing several supraglottic airway devices focusing on "true laypersons" without any background in healthcare, and in some cases without basic first-aid training.

The participants in previous studies, in addition to a more healthcare oriented background, also received a longer and more comprehensive training session prior to intonation. Few studies have focused on the use of supraglottic airway devices by subjects having received minimal training prior to intubation $[9,18,19]$. Jokela et al. used a short educational video-clip for instruction and demonstrated that inexperienced first responder trainees could secure the airway in a manikin with the

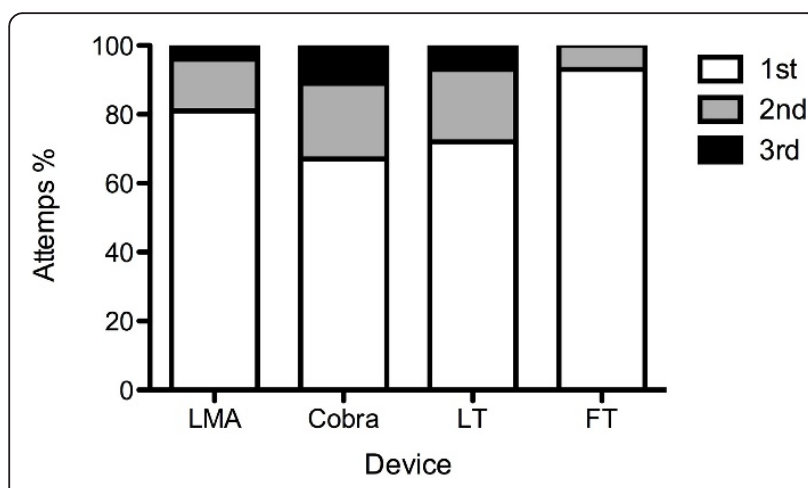

Figure 4 Number of attempts needed dependent on the supraglottic device. FT required the fewest attempts, followed by the LMA, the LT and the Cobra. No statistically significant differences could be shown between the FT and the LMA ( $p>$ 0.05). Compared to the FT, the Cobra* $(p<0.0001)$ and $L T^{\#}(p<$ $0.05)$ needed significantly more attempts for correct placement. No significant differences between the Cobra, LMA, and LT were found. Data are presented in percentage.
FT and the LT with a comparable success rate [10]. In contrast, we found a significantly better performance of laypersons operating the FT. A similar result has previously been reported for paramedical students [20], non-anesthetic medical staff and non-medical staff $[9,12,19]$.

Also in accordance with our results, the success rate for intubation attempts and the insertion times for the COBRA device have previously been demonstrated to be lower than for other devices, as well as being critically dependent upon operator experience [15].

The present study also observed another important problem with the COBRA-device: in 9 cases it was inserted $180^{\circ}$ rotated, with the airway aperture dorsal instead of ventral. In the Cobra, the airway aperture may be overseen due to the lack of curvature in the stem and the fact that the aperture itself appears covered by some bars. Furthermore, the blocking balloon encircles the distal part of the device. Consequently, the COBRA device performed worse than the LM even when inserted by experienced anesthetists [13].

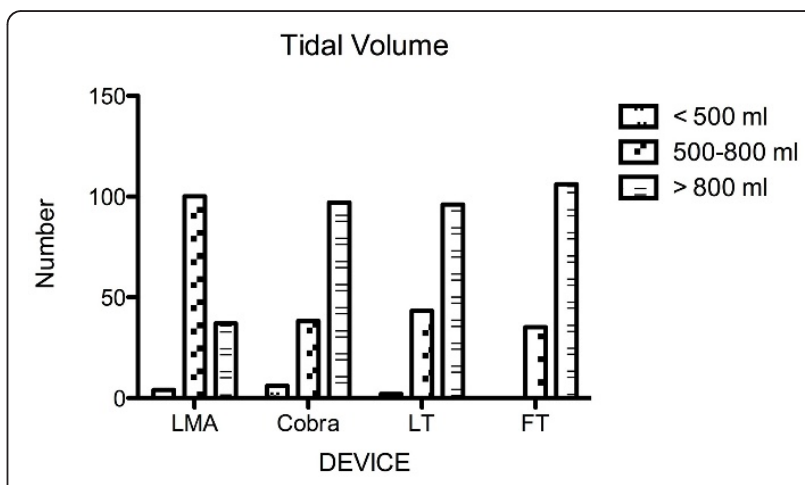

Figure 5 Applied tidal volumes dependent on the supraglottic device. No significant differences in the application of "sufficient" tidal volumes $(>500 \mathrm{ml})$ were found among the 4 devices $(p=$ 0.08). Analysis of subgroups with tidal volumes of $500-800 \mathrm{ml}$ and $>$ $800 \mathrm{ml}$ found significantly smaller but sufficient tidal volumes (500$800 \mathrm{ml}$ ) in $L M A^{*}$ ventilated patients $(p<0.0001)$. Data are presented in numbers. 
Table 3 Influence of sequence on insertion time and number of attemps

\begin{tabular}{lccccc}
\hline Sequence & $\mathbf{1}$ & $\mathbf{2}$ & $\mathbf{3}$ & $\mathbf{4}$ & $\mathbf{P}$ value \\
\hline Time [s] & & & & & \\
LMA & $28 \pm 21.4$ & $19.7 \pm 15.8$ & $25.3 \pm 25.9$ & 21 & 0.36 \\
Cobra & $26.7 \pm 18.4$ & $34.8 \pm 35.1$ & $29.6 \pm 25.3$ & $35.9 \pm 30.5$ & 0.47 \\
LT & $19.6 \pm 13.4$ & $20.74 \pm 19.9$ & $23.4 \pm 13.9$ & $23.8 \pm 17.4$ & 0.57 \\
FT & $22.5 \pm 25.1$ & $15.7 \pm 5.9$ & $14.9 \pm 5.7$ & $18.4 \pm 11.7$ & 0.13 \\
Attempts [n] & & & & $0.12 \pm 0.53$ \\
LMA & $1.36 \pm 0.59$ & $1.14 \pm 0.35$ & $1.22 \pm 0.54$ & $1.58 \pm 0.77$ & 0.52 \\
Cobra & $1.37 \pm 0.59$ & $1.45 \pm 0.78$ & $1.37 \pm 0.59$ & $1.48 \pm 0.7$ & 0.46 \\
LT & $1.25 \pm 0.56$ & $1.32 \pm 0.58$ & $1.36 \pm 0.59$ & $1.08 \pm 0.28$ & 0.19 \\
FT & $1.02 \pm 0.35$ & $1.02 \pm 0.16$ & $1.02 \pm 0.16$ & & \\
\hline
\end{tabular}

No significant difference between LMA, Cobra, LT and FT regarding the sequence of use could be demonstrated for the time of insertion or the attemps needed. Data are presented as means +/- standard deviation

Although in our study an attempted upside-down insertion of the COBRA-device was immediately recognized and corrected by the participants, it remains questionable whether in the setting of a real resuscitation lay responders under stress would act similarly. The difficulties described above likely contribute to the participants estimation of the COBRA as the most difficult and inconvenient device. The LT and FT were judged as most intuitive.

Success rates for the LT as observed in our study are similar to those reported in the literature. Although Wrobel et al. indicated that lack of clinical experience could halve the initial success rate when the LT is inserted by non-anesthesiologists, our results do not reveal such a low success rate for the LT [21]. Similarly, in an out-of-hospital trial investigating LT airway management by paramedics and emergency physicians, both performed equally well when using the $\mathrm{LT}$ as a rescue device after failed endotracheal intubation or as an initial airway [22]. The majority of users were relatively inexperienced, with less than $5 \mathrm{LT}$ placements. In accordance with our data first attempt success was about $78 \%$. Moreover, in undergraduate students without medical training a high success rate of $80 \%$ for the King LT$\mathrm{D}$ could be demonstrated using "on-site" minimal scripted telephonic instruction [17].

In a manikin untrained laypersons can achieve a secured airway with the LMA or LMA-classic even without detailed background knowledge about the tool. In fact, minimal theoretical instruction and practical skill training significantly improved their performance [9]. LMA supreme, in novice hands, systematically promoted easier ventilation of better quality than the facemask in morbidly obese patients showing difficult mask ventilation predictors [23]. The authors suggest that the LMA Supreme could be considered as a standard airway management tool for both elective and rescue airway management. A $100 \%$ success rate in manikin and a
$64 \%$ success rate in the field among adult out-of-hospital non-traumatic cardiac arrest have been reported in paramedics with manikin training only [20]. Timmermann et al. demonstrated that medical students could establish ventilation with the intubation laryngeal mask significantly more successful and rapidly compared to bag-valve ventilation in anesthetized patients [24]. In a single trial "mouth-to-mouth ventilation" via a pocket face-mask was compared to the LMA provided by basic trained nurses. Success rate were $51 \%$ for "mouth-tomouth ventilation" via pocket-face-mask and $95 \%$ for the LMA [11]. Recently Adelborg et al. proved "mouthto-mouth" ventilation to reduce interruptions in chest compressions and producing a higher proportion of effective ventilation during lifeguard CPR, compared to "mouth-to-pocket-mask" or "bag-valve-mask" ventilation [25]. In consideration of these trials and acceptance of our results supraglottic airway devices might be an excellent or even superior alternative to established ventilation provided by lay responders.

We acknowledge that our study is subject to several limitations. Our results suggest that the majority of supraglottic airway devices are well suited to use by laypersons. This might imply in a preclinical emergency setting that laypersons, regardless of experience, can provide a secured airway and hence bridge the time until a professional resuscitation team is on site. On the other hand, it remains to be proven whether laypersons in a real resuscitation scenario, with its associated challenges, can still rely on their intuition. Secondly, it is beyond the scope of the present study to compare different educational modalities (classic, video, pictogram, practical or combined) with regard to their effectiveness $[14,20]$. Thirdly, skills when newly acquired and without subsequent practice are known to deteriorate [26], and it would therefore be worthwhile re-evaluating all participants in the near future. Recent findings however are promising: a single combined theoretical, video assisted 
and practical tutorial enables paramedical students to operate different supraglottic airway devices in a mannequin with retention of skills close to $100 \%$ after three months, even if no further clinical or manikin training is provided [18,27].

\section{Conclusion}

In conclusion, we show that in a manikin resuscitation scenario, airway management can be safely and effectively performed by laypersons. The intuitive nature and ease of use of supraglottic airway devices clearly leads to high success rates and this is one of their key benefits. The present study shows that these benefits and success rates also extend to members of the public without formal healthcare training, and even without any knowledge of first-aid. Together with the positive attitude expressed by the participants towards such devices, our results recommend the incorporation of supraglottic airway devices in first aid and BLS courses.

\section{Disclosure}

The authors declare that they have no competing interests.

\section{Author details}

${ }^{1}$ Department of Anesthesiology, University Hospital Aachen, Aachen, Germany. '2Department of Pediatrics and Neonatology, University Hospital Aachen, Aachen, Germany.

\section{Authors' contributions}

GS carried out conception and design, interpretation of data and drafted the manuscript. CS and SR participated in interpretation and helped to draft the manuscript. MC and MS critical revised the manuscript and supervised statistical analysis. MA allocated data and supervised setting and participants. $\mathrm{RR}$ approved the final version and NZ co-conceived, critical revised the manuscript and allocated data. All authors read and approved the final manuscript.

Received: 18 August 2011 Accepted: 24 October 2011

Published: 24 October 2011

\section{References}

1. Handley JA, Handley AJ: Four step CPR-improving skill retention. Resuscitation 1998, 36:3-8.

2. Ornato JP, Hallagan LF, McMahan SB, Peeples EH, Rostafinski AG: Attitudes of BCLS instructors about mouth-to-mouth resuscitation during the AIDS epidemic. Ann Emerg Med 1990, 19:51-156.

3. Brenner BE, Van DC, Cheng D, Lazar LJ: Determinance of refluctance of to perform CPR among residents and applicants: the impact of experiences on helping behaviors. Resuscitation 1997, 35:203-211.

4. Nolan JP, Soar J, Zideman DA, Biarent D, Bossaert LL, Deakin C, Koster RW, Wyllie J, Böttiger B: European Resuscitation Council Guidelines for Resuscitation 2010. Resuscitation 2010 [http://www.cprguidelines.eu/2010/].

5. Choyce A, Avidan MS, Patel C, Harvey A, Timberlake C, McNeilis N, Glucksman E: Comparison of laryngeal mask and intubating laryngeal mask insertion by the naïve intubator. $\mathrm{Br} J$ Anaesth 2000, 84:103-105.

6. Choyce A, Avidan MS, Shariff A, Del Aguila M, Radcliffe JJ, Chan T: A comparison of the intubating and standard laryngeal mask airways for airway management by inexperienced personnel. Anaesthesia 2001, $56: 357-60$
7. Timmermann A, Cremer S, Heuer J, Braun U, Graf BM, Russo SG: Laryngeal mask LMA Supreme. Application by medical personnel inexperienced in airway management. Anaesthesist 2008, 57:970-75.

8. Heuer JF, Barwing J, Eich C, Quintel M, Crozier TA, Roessler M: Initial ventilation through laryngeal tube instead of face mask in out-ofhospital cardiopulmonary arrest is effective and safe. Eur J Emerg Med 2010, 17:10-15.

9. Bickenbach J, Schälte G, Beckers S, Fries M, Derwall M, Rossaint R: The intuitive use of laryngeal airway tools by first year medical students. BMC Emerg Med 2009, 22;9:18.

10. Jokela J, Nurmi J, Grenzwuerker HV, Castren M: Laryngeal tube and intubating laryngeal mask insertion in a manikin by first-responder trainees after a short video-clip demonstration. Prehosp Disaster Med 2009, 24:63-66

11. Alexander R, Chinery JP, Swales H, Sutton D: "Mouth to mouth ventilation": a comparison of the laryngeal mask airway with the Laerdal Pocket Facemask. Resuscitation 2009, 80:1240-3.

12. Burgoyne L, Cyna A: Laryngeal mask vs intubating laryngeal mask: insertion and ventilation by inexperienced resuscitators. Anaesth Intensive Care 2001, 29:604-608.

13. Kurola J, Pere P, Nieme-Murola L, Silvast P, Rautoma P, Catren M: Comparison of airway management with the intubating laryngeal mask, laryngeal tube and CobraPLA ${ }^{\oplus}$ by paramedical students in anaesthetized patients. Acta Anaesthesiol Scand 2006, 50:40-44.

14. Kurola J, Harve H, Kettunen T, Laakso JP, Gorski J, Paakkonen H, Silvast T: Airway management in cardiac arrest-comparison of the laryngeal tube, tracheal intubation and bag-valve mask ventilation in emergency medical training. Resuscitation 2004, 61:149-53.

15. Akca O, Anumpama W, Sengupta P, Durrani J, Hanni K, Wenke M, Yücel Y, Lenhardt R, Doufas AG, Sessler DI: The new perilaryngeal airway $\left(\right.$ CobraPLA $\left.{ }^{\mathrm{TM}}\right)$ is as efficient as the laryngeal mask airway $\left(\mathrm{LMA}^{\mathrm{TM}}\right)$ but provides better airway sealing pressure. Anesth Analg 2009, 99:272-8.

16. Van Zundert A, Al-Shaikh B, Brimacombe J, Koster J, Koning D, Mortier E: Comparison of three dispoable extraglottic airway devices in spontaneously breathing patients. Anesthesiology 2006, 104:1165-1169.

17. Beauchamp G, Phrampus P, Guyette FX: Simulated rescue airway use by laypersons with scripted telephonic instruction. Resuscitation 2009, 80(8):925-9.

18. Murray MJ, Vermeulen MJ, Morrison LJ, Waite T: Evaluation of prehospital insertion of the laryngeal mask airway by primary care paramedics with only classroom mannequin training. CJEM 2002, 5:338-43.

19. Levitan RM, Ochroch EA, Stuart S, Hollander JE: Use of the intubating laryngealmask airway by medical and nonmedical personnel. Am J Emerg Med 2000, 18:12-6.

20. Weksler N, Tamopolski A, Klein M, Schily M, Rozentsveig V, Shapira AR, Gurman GM: Insertion of the endotracheal tube, laryngeal mask airway and oesophageal-tracheal combitube. A 6-month comparative prospective study of acquisition and retention skills by medical students. Eur J Anaesthesiol 2005, 22:337-40.

21. Wrobel M, Grundmann U, Wilhelm W, Wagner S, Larsen R: Laryngeal tube versus laryngeal mask airway in anaesthetised non-paralysed patientsA comparison of handling and postoperative morbidity. Anaesthesist 2004 53:702-8.

22. Dengler V, Wilde P, Byhahn C, Mack MG, Schalk R: Prehospital airway management of laryngeal tubes: Should the laryngeal tube Swith gastric drain tube be preferred in emergency medicine? Anaesthesist 2011, 60:135-8.

23. Abdi W, Dhonneur G, Amathieu R, Adhoum A, Kamoun W, Avenel A, Sebbah JL, Combes X, Dhonneur G: LMA supreme versus facemask ventilation performed by novices: a comparative study in morbidly obese patients showing difficult ventilation predictors. Obes Surg 2009, 19:1624-30.

24. Timmermann A, Russo SG, Crozier TA, Eich C, Mundt B, Albrecht B, Graf BM: Novices ventilate and intubate quicker and safer via intubating laryngeal mask than by conventional bag-mask ventilation and laryngoscopy. Anesthesiology 2007, 107:570-6.

25. Adelborg K, Dalgas C, Grove EL, Jørgensen C, Al-Mashhadi RH, Lofgren B: Mouth-to-mouthventilation is superior to mouth-to-pocket mask and bag-valve-mask ventilation during lifeguard CPR: a randomized study. Resuscitation 2011, 82:618-22. 
26. Vertongen VM, Ramsay MP, Herbinson P: Skills retention for insertion of the combitube and laryngeal mask airway. Emerg Med 2003, 15:459-64.

27. Ruetzler K, Roessler B, Potura L, Priemayr A, Robak O, Schuster E, Frass M: Performance and skill retention of intubation by paramedics using seven different airway devices-a manikin study. Resuscitation 2011, 82:593-7.

doi:10.1186/1757-7241-19-60

Cite this article as: Schälte et al:: Laypersons can successfully place supraglottic airways with 3 minutes of training. A comparison of four different devices in the manikin. Scandinavian Journal of Trauma,

Resuscitation and Emergency Medicine 2011 19:60.

Submit your next manuscript to BioMed Central and take full advantage of:

- Convenient online submission

- Thorough peer review

- No space constraints or color figure charges

- Immediate publication on acceptance

- Inclusion in PubMed, CAS, Scopus and Google Scholar

- Research which is freely available for redistribution

Submit your manuscript at www.biomedcentral.com/submit
Ciomed Central 